\title{
Effects of Preoperative Anxiety on Intraoperative Hemodynamics and Postoperative Pain
}

\author{
Aysegul Bayrak1, Gonul Sagiroglu² and Elif Copuroglu² \\ ${ }^{1}$ Department of Anesthesiology, Yozgat Yerkoy Government Hospital, Yozgat, Turkey \\ 2 Department of Anesthesiology, Trakya University, Faculty of Medicine, Edirne, Turkey
}

\begin{abstract}
Objective: To determine the effects of the level of the anxiety of the patients on the intraoperative hemodynamic parameters and postoperative pain, patient satisfaction and the stay period at the hospital.

Study Design: A descriptive study.

Place and Duration of Study: General Surgery, Faculty of Medicine, Trakya University, Edirne, Turkey, from December 2015 to February 2016.

Methodology: Seventy-two patients were operated for elective cholecystectomy. They were asked to answer state-trait anxiety inventory (STAI) questionnaire. The patients were classified into two groups as high and low anxiety levels. The targeted variables were compared.

Results: There has not been found any significant relationship between the level of anxiety and age, gender, marial status, level of education, profession, general anesthesia, comobidity and postoperative shivering. However, patients with high preoperative anxiety scores had unstable hemodynamic parameters (arterial pressure, heart rate, peripheral oxygen saturation) intraoperatively, increased postoperative pain and analgesic consumption with dissatisfaction.

Conclusion: Preoperative anxiety might cause hemodynamic problems in the intraoperative period, increased analgesic need and lower postoperative satisfaction of the patients in the postoperative period. It would be better to dispel the preoperative anxiety by conselling patient regar anesthesia, surgeon, and the institute.
\end{abstract}

Key Words: Anxiety, Hemodynamic changes, Postoperative pain.

How to cite this article: Bayrak A, Sagiroglu G, Copuroglu E. Effects of preoperative anxiety on intraoperative hemodynamics and postoperative pain. J Coll Physicians Surg Pak 2019; 29(9):868-73.

\section{INTRODUCTION}

Anxiety is an inherent response to the unforeseeable and eventual disqueiting conditions/characteristics of the preoperative stage; substantially in the course of the patient's first acquaintance with surgery and next one or two meetings. ${ }^{1}$ The frequency of preoperative anxiety is described in Western countries, is between $60-80 \%$. In some other studies, this was found to be higher, $11-80 \%{ }^{2}$ Diverse researches have shown that dread about surgery is related to disabled psychosocial and physical healing, like raised scores of postoperative pain. ${ }^{3}$ Preoperative anxiety or due to excessive reflex sympathetic activity during laryngoscopy and intubation hemodynamic changes (tachycardia, hypertension, arrhythmia) may result in the cancellation of the planned surgery. 4 Preoperative informing is the first step in preparing the patient in psychological terms for surgery. Giving information in the preoperative period, reduces anxiety,

Correspondence to: Dr. Gonul Sagiroglu, Department of Anesthesiology, Trakya University, Faculty of Medicine,

Edirne, Turkey

E-mail: gonulsagiroglu45@gmail.com

Received: June 14, 2018; Revised: January 17, 2019; Accepted: March 18, 2019 fear, development of depression and postoperative analgesic requirements; and shortens the length of hospital stay. ${ }^{5}$ All these lead to obstruction of health services and dissatisfaction of patients. ${ }^{2}$ Accordingly, preoperative evaluation of surgical fear could supply necessary data for progress perioperative nursing and could be initial pace for aimed operation. ${ }^{3}$

The medical world still does not have an optimal scale to assess preoperative anxiety, as different types of questionnaires can be used to determine anxiety.6,7 While pointing to the high level of anxiety during the evaluation, high anxiety scale (STAI-II) shows an anxious personality traits. ${ }^{8}$ The general acceptance is that Spielberger's state-trait anxiety inventory (STAI) as the gold standard for measuring the preoperative anxiety. Many researches had approved the correctness of STAI to evaluate preoperative anxiety. The rationale of this study was to prevent intraoperative complication, needs of analgesic consumption, and hospital stay.

The objective of this study was to determine the effects of the level of the preoperative anxiety of the patients on the intraoperative hemodynamic parameters and postoperative pain, patient satisfaction and the stay period at the hospital. 


\section{METHODOLOGY}

This study was conducted in the operating room of the Trakya University Hospital after approval from University's Ethics Review Committee (Reference number: TÜTFBAEK 2015/198).

Seventy-two patients in an age range of 18 to 80 years and of American Society of Anesthesiologists (ASA) physical status I, II or III operated for elective cholecystectomy between December 2015 and February 2016 were included in this study. The exclusion criteria were alcohol or drug abuse, a history of psychiatric illness, a disease of the central nervous system, no psychotropic medication, patients with more than 3 unanswered questions on the STAI questionnaire, and patients with normal anxiety scores (in the range of 37 to 45 ).

Cardiology consultation was requested in patients having coronary artery disease. Coronary stent was placed in one patient. Nephrology consultation was requested for patients with hypertension. Two patients who did not received medication yet, and two patients receiving irregular drug treatment were treated on regular antihypertensive medication in accordance with the nephrology recommendations. Addition of a second antihypertensive agent to regulate hemodynamic values was needed for one patient. All patiens having hypertension were operated after regulating the daily values. According to the endocrine consultation, oral antidiabetic therapy of the patients with diabetes mellitus were switched to crystalised insulin and were operated after the recommended value of the daily blood glucose profile was reached.

Demografic data of patients [age, gender, marital status, having children, education level (literate, primary education, high school, university), professional group (retired, civil servant, worker, self employment, unemployment), comorbidity and previous experience of anesthesia were recorded. Taking into account the differences in the educational and sociocultural levels of the patients, inventory forms were readout to patients and the answers marked.

The STAI was used to measure the anxiety levels. It consists of two sections, with first section measuring state anxiety, and the second one measuring trait anxiety. STAI-I which describes how individual feels himself/herself in a particular situation and certain conditions, with needs to respond to his/her feelings about the situation in which he/she is living. STAI-II usually requires the expression of how the individual feels. Each with two scale has 20 items. Both scales can be applied at the same time. No special training is required to perform the scale which can be applied to consicious individuals over 14 years of age. 5

Patients with anxiety score of 36 or less were evaluated as having low anxiety scored and those with anxiety score of 46 or higher were rated as having high anxiety scored. According to the calculated scores, patients were divided into two groups as low anxiety-score group (Group $1=35$ patients) and high anxiety-score group (Group $2=37$ patients). No premedication was used for any of the patients. Standard monitoring (systolic arterial pressure (SAP), diastolic arterial pressure (DAP), mean arterial pressure (MAP), heart rate, peripheral oxygen saturation $\left(\mathrm{SpO}_{2}\right)$, and ECG were applied. The first measurement was recorded as the initial value. Hemodynamic parameters were measured noninvasively in basal, $5,15,30,60,90,120$, and $150^{\text {th }}$ minutes in the intraoperative period.

Hypotensive episodes (decrease in MAP below $60 \mathrm{mmHg}$ ) were administered with solution of a bolus of isotonic fluid solution and intravenous (IV) $10 \mathrm{mg}$ of ephedrine bolus. Bradycardia (heart rate $<45$ beats/ minute) was treated with IV atropine at a bolus dose of $0.5 \mathrm{mg}$.

General anesthesia was induced with $1 \mu \mathrm{g} / \mathrm{kg}$ of fentanyl and $5-7 \mathrm{mg} / \mathrm{kg}$ of thiopental IV. Anesthesia was maintained with end-tidal concentration of 0.5 to $2 \%$ sevoflurane. Tracheal intubation was facilitated with IV $0.6 \mathrm{mg} / \mathrm{kg}$ rocuronium bromide, bolus doses of rocuronium were given $0.15 \mathrm{mg} / \mathrm{kg}$ as required. End-tidal carbon dioxide $\left(\mathrm{EtCO}_{2}\right)$ was maintained between 32 and $40 \mathrm{mmHg}$. At the end of the operation, neuromuscular blockadge was reversed by the administration of IV neostigmine at a dose of $0.7 \mathrm{mg} / \mathrm{kg}$ and atropine at a dose of $0.02 \mathrm{mg} / \mathrm{kg}$.

Pain intensity was evaluated by using a $10 \mathrm{~cm}$ numerical rating scales (NRS), where $0 \mathrm{~cm}$ represented no pain and $10 \mathrm{~cm}$ represented worst possible pain. Analgesic effectivity was controlled by NRS at baseline, 1, 2, 4, 8, 12 and 24 hours after surgery. Tramadol was used via patient controlled analgesia pump; $20 \mathrm{mg} / \mathrm{h}$ basal infusion, bolus dose $10 \mathrm{mg}$, lockout interval of 10 minutes and a maximum allowable dose $400 \mathrm{mg}$ for 4 hours. Also the tramadol consumption at 4,12 and $24^{\text {th }}$ hours were recorded. If the NRS score was more than $4 \mathrm{~cm}$, patients administered an IV $20 \mathrm{mg}$ tenoxicam.

Patients' satisfaction scores were given as "bad", "mild", "good", "excellent", while they were asked to use numbers from 1 to 10 to evaluate their anxiety level. 9 Intensity of pain, satisfaction of the patient for postoperative pain treatment and general pain management in the hospital were recorded through a specially arranged survey (Appendix 1). The survey is a revised version of the revised American pain society patient outcome questionnaire (APS-POQ-R), which was created to assess pain management among adult patients. 9 The manager used the survey to record the undermentioned information: Pain scores (motionless, while motion, minimum pain, maximum pain, percentage of severe pain time period) and pain scores when doing activities in bed (such as turning, standing up, repositioning) and out of bed (such as walking, sitting in a chair). 
Furthermore, the survey allowed patients to express what they feel during pain (anxious, depressed, frightened, helpless) and also detected pain which led to side effects (nausea, drowsiness, itching, dizziness) and treatmen of pain relief. All evaluations were made by giving scores from 1 to 10 . the smallest value was recorded as 1 , the largest value was 10 . APS-POQ-R is a questionnaire developed to evaluate adult patient pain administration and activity. The survey evaluated quality's 6 views, (1) intensity of pain and reassurance; (2) effects of pain on moving, sleeping, and how to feel; (3) side effects; (4) help for information about pain therapy; (5) ability to participate in pain treatment decisions; (6) use of nonmedical practices. ${ }^{9}$ Hospital stay and number of patients with postoperative shivering were recorded.

All analyses were performed using the SPSS Statistical Package 20.0 (SPSS Inc., Chicago, IL). The compliance of the data of the continuous measurements to a normal distribution was examined by the Kolmogorov-Smirnov test. Qualitative data were expressed as frequencies and percentages. Group differences for categorical variables were examined by Chi-square or Fisher's exact test, as appropriate. Whereas, in cases of normal distribution, group differences for continuous data were examined by independent-samples t-test, for nonnormally distributed data a Mann-Whitney U-test was applied. The data are presented as mean and standard deviation (SD) for continuous variables or as frequencies and percentages for categorical variables. P-values $<0.05$ were considered statistically significant.

\section{RESULTS}

The comparison of the baseline characteristics between groups showed no significant difference (Table I).

The age distributions of patients were $52.36 \pm 14.49$ years in Group 1 and $59.35 \pm 16.68$ years in Group 2 . Although the anxiety score seemed to increase in proportion to age, this difference was not statistically significant. There were only two unmarried patients, one in each group. All the other patients were married and there was no statistically significant effect of marital status on anxiety (Table I).

According to the STAI-I and STAI-II questionnaires, the mean instant anxiety score of 72 patients was 42.01 $\pm 15.04 ; 38.51 \pm 4.19$, respectively. The anxiety scores in Group I were significantly lower than Group II when the STAI-I and STAI-II values of the groups were compared $(p<0.001)$.

When the effect of anxiety on hemodynamic parameters is examined; patients with high anxiety scores had higher values of arterial blood pressure and heart rate. Baseline, 15, 30,60th $\min$ SAP - heart rate values and baseline, 15, 30th min DAP - MAP values of Group 2 were statistically significantly higher than Group 1
Table I: Baseline clinical characteristics of the study population.

\begin{tabular}{|c|c|c|c|}
\hline Variable & Group $1(n=35)$ & Group $2(n=37)$ & p-value \\
\hline Age (years)a & $52.66 \pm 14.49$ & $59.35 \pm 16.68$ & 0.074 \\
\hline Weight (kg)a & $77.26 \pm 14.82$ & $80.81 \pm 15.11$ & 0.318 \\
\hline Height $(\mathrm{cm})^{\mathrm{a}}$ & $164.69 \pm 0.1$ & $166.05 \pm 0.08$ & 0.533 \\
\hline Body mass index $\left(\mathrm{kg} / \mathrm{m}^{2}\right)^{\star}$ & $28.44 \pm 4.69$ & $29.34 \pm 5.58$ & 0.46 \\
\hline \multicolumn{4}{|l|}{ Gender $\mathrm{n}(\%)^{\mathrm{b}}$} \\
\hline Female & $25(71.4)$ & $23(62.2)$ & 0.56 \\
\hline Male & $10(28.6)$ & $14(37.8)$ & \\
\hline \multicolumn{4}{|l|}{$A S A^{b}$} \\
\hline I & $19(54.3)$ & $13(35.1)$ & 0.122 \\
\hline II & $13(37.1)$ & $15(40.5)$ & \\
\hline III & $3(8.6)$ & $9(24.3)$ & \\
\hline \multicolumn{4}{|l|}{ Comorbidity disease $n(\%)^{b}$} \\
\hline Hypertension & $0(0)$ & $4(10.8)$ & 0.306 \\
\hline Diabetes mellitus & $8(22.9)$ & $7(18.9)$ & \\
\hline Chronic obstructive lung disease & $3(8.6)$ & $4(10.8)$ & \\
\hline Coronary artery disease & $4(11.5)$ & $2(5.4)$ & \\
\hline \multicolumn{4}{|l|}{ Familial status $\mathrm{n}(\%)^{\mathrm{b}}$} \\
\hline Married & $34(97.1)$ & $36(97.3)$ & 1 \\
\hline Divorced & $1(2.9)$ & $1(2.7)$ & \\
\hline Children & $34(97.1)$ & $36(97.3)$ & 1 \\
\hline \multicolumn{4}{|l|}{ Education level; $n(\%)^{b}$} \\
\hline Basic education & $28(80)$ & $32(86.1)$ & 0.796 \\
\hline Higher education & $7(20)$ & $5(13.9)$ & \\
\hline Previous experience of anesthesiab & $22(62.9)$ & $24(64.9)$ & 1 \\
\hline Hospital stay (days)a & $2.03 \pm 1.92$ & $3.03 \pm 2.87$ & $0.047^{*}$ \\
\hline \multicolumn{4}{|l|}{ Patient satisfaction; $\mathrm{n}(\%)^{\mathrm{b}}$} \\
\hline Bad & $0(0)$ & $5(13.5)$ & $<0.001^{*}$ \\
\hline Mild & $7(20)$ & $19(51.4)$ & \\
\hline Good & $19(54.3)$ & $13(35.1)$ & \\
\hline Excellent & $9(25.7)$ & $0(0)$ & \\
\hline
\end{tabular}

(Table II). When in the intra-group comparison of both groups, baseline arterial blood pressures and heart rate values and values with $5,15,30,60^{\text {th }}$ min compared was found a statistically significant decrease (Table II).

When anxiety level was increased, a decrease in $\mathrm{SpO}_{2}$ level was observed. $\mathrm{SpO}_{2}$ values at baseline, 30 and 60th minutes of Group 1 were statistically significantly higher than those of Group 2 (Table II). The increase in the $5,15,30$ and $60^{\text {th }}$ minutes compared to the baseline value in the intra-group comparison of Group 1 was statistically significant. In the intra-group comparison of Group 2, $\mathrm{SpO}_{2}$ values at 15,30 and $60^{\text {th }}$ minutes according to basal values were statistically significantly higher (Table II).

At first 24-hour postoperative period, VAS scores at all time points of Group 1 were statistically significantly lower than Group $2(p<0.001)$. There was a statistically significant decrease in VAS scores at all other times compared to the first hour in the intra-group comparison of both group ( $p<0.001$, Table III).

In Group 1, tramadol consumptions at 4,12 , 24th hour $(p<0.001 ; p=0.004 ; p=0.002)$ was significantly lower 
Table II: Hemodynamic changes of the two groups.

\begin{tabular}{|c|c|c|c|c|c|c|c|c|}
\hline Parameters & Basal & $5 \mathrm{~min}$ & $15 \mathrm{~min}$ & $30 \mathrm{~min}$ & $60 \mathrm{~min}$ & $90 \mathrm{~min}$ & $120 \mathrm{~min}$ & $150 \mathrm{~min}$ \\
\hline \multicolumn{9}{|l|}{ Systolic Arterial Pressure $(\mathrm{mmHg})$} \\
\hline Group 1 & $148(106-207)$ & $119(90-174)$ & $118(78-180)$ & $120.5(83-184)$ & $128.5(92-158)$ & $130(99-178)$ & $121.50(102-130)$ & $128(128-128)$ \\
\hline Group 2 & $172(115-220)$ & $131(92-235)$ & $140(92-218)$ & $149(97-228)$ & $140(93-183)$ & $144(113-172)$ & $139(114-144)$ & $144(140-148)$ \\
\hline P-value & $0.11^{*}$ & 0.124 & $<0.001^{*}$ & $<0.001^{*}$ & 0.10 & 0.134 & 0.088 & 0.221 \\
\hline \multicolumn{9}{|l|}{ Diastolic Arterial Pressure $(\mathrm{mmHg})$} \\
\hline Group 1 & $82(58-118)$ & $76(56-118)$ & $74(50-108)$ & $77.50(52-102)$ & $78(53-95)$ & $78(55-98)$ & $71(60-83)$ & $76(76-76)$ \\
\hline Group 2 & $92(57-139)$ & $78(54-174)$ & $84(56-161)$ & $81(58-145)$ & $78(58-130)$ & $84(65-115)$ & $84(62-99)$ & $86(84-88)$ \\
\hline P-value & $0.018^{*}$ & 0.217 & $<0.001^{*}$ & $0.026^{*}$ & 0.461 & 0.146 & 0.058 & 0.221 \\
\hline \multicolumn{9}{|l|}{ Mean Arterial Pressure $(\mathrm{mmHg})$} \\
\hline Group 1 & $108(77-139)$ & $89(71-139)$ & $88(64-132)$ & $94(68-127)$ & $97.5(63-116)$ & $100(71-115)$ & $92.79(83-116)$ & $95.97(86-106)$ \\
\hline Group 2 & $126(86-154)$ & $96(72-191)$ & $103(65-183)$ & $112(75-163)$ & $106(74-148)$ & $106.50(74-132)$ & $104(81-134)$ & $113(80-126)$ \\
\hline P-value & $0.006^{*}$ & 0.106 & $<0.001^{*}$ & $0.003^{*}$ & 0.174 & 0.152 & 0.345 & 0.439 \\
\hline \multicolumn{9}{|l|}{ Heart Rate (beats/min) } \\
\hline Group 1 & $80(54-102)$ & $76(51-99)$ & $70(52-100)$ & $70.50(50-103)$ & $72.50(50-88.50)$ & $72(52.03-85)$ & $72(64.75-88.53)$ & $73.40(66.61-80.20)$ \\
\hline Group 2 & $90(50-125)$ & $85(49-110.57)$ & $90(60.27-115)$ & $84(59.19-105)$ & $80(60-110)$ & $71(53-92.37)$ & $68.31(57.30-91)$ & $71.57(62.50-80.64)$ \\
\hline P-value & $0.003^{*}$ & 0.036 & $<0.001^{*}$ & $<0.001^{*}$ & 0.080 & 0.597 & 0.871 & 1.00 \\
\hline \multicolumn{9}{|l|}{ Peripheral Oxygen Saturation } \\
\hline Group 1 & $98(93-100)$ & $99(95-100)$ & $99(95-100)$ & $99(96-100)$ & $99(96-100)$ & $100(98-100)$ & $100(100-100)$ & $100(100-100)$ \\
\hline Group 2 & $97(92-100)$ & $98(96-100)$ & $99(96-100)$ & $99(96-100)$ & $99(95-100)$ & $99(95-100)$ & $100(99-100)$ & $98.5(97-100)$ \\
\hline P-value & $0.011^{*}$ & $0.011^{*}$ & 0.281 & $0.011^{*}$ & $0.007^{*}$ & 0.083 & 0.143 & 0.48 \\
\hline
\end{tabular}

Table III: Changes of visual analog scale scores $(0 \mathrm{~cm}=$ no pain, $10 \mathrm{~cm}=$ worst pain imaginable $)$ compared to the basal values according to the time postoperatively. Data presented as median (IGR).

\begin{tabular}{|c|c|c|c|c|c|}
\hline \multirow[t]{2}{*}{ Time (hours) } & \multicolumn{2}{|c|}{ Visual analogue scala } & \multirow{2}{*}{$\begin{array}{c}\text { Grup } 1 \text { vs. Grup } 2 \\
(p \text {-value })^{a}\end{array}$} & \multirow{2}{*}{$\begin{array}{c}\text { The comparation intragroup } \\
\text { of postoperative group } 1 \\
\text { (p-value })^{\mathrm{b}}\end{array}$} & \multirow{2}{*}{$\begin{array}{c}\text { The comparation intragroup of } \\
\text { postoperative group } 2 \\
(p \text {-value })^{b}\end{array}$} \\
\hline & Group $1(n=35)$ & Group $2(n=37)$ & & & \\
\hline 1 & $3(1-6)$ & $4(2-8)$ & $<0.001^{*}$ & $<0.001^{* *}$ & $<0.001^{\star \star \star}$ \\
\hline 2 & $2(1-5)$ & $4(2-6)$ & $<0.001^{*}$ & $<0.001^{* *}$ & $<0.001^{* * *}$ \\
\hline 4 & $2(1-4)$ & $4(3-6)$ & $<0.001^{*}$ & $<0.001^{* *}$ & $<0.001^{* * *}$ \\
\hline 8 & $2(1-4)$ & $3(2-4)$ & $<0.001^{*}$ & $<0.001^{* *}$ & $<0.001^{* * *}$ \\
\hline 12 & $2(1-3)$ & $3(1-4)$ & $<0.001^{*}$ & $<0.001^{* *}$ & $<0.001^{* * *}$ \\
\hline 16 & $1(0-2)$ & $2(1-3)$ & $<0.001^{*}$ & $<0.001^{* *}$ & $<0.001^{* * *}$ \\
\hline 24 & $1(0-3)$ & $2(1-3)$ & $<0.001^{*}$ & $<0.001^{\star *}$ & $<0.001^{* * *}$ \\
\hline
\end{tabular}

Group 1: Low anxiety scored group; Group 2: High anxiety scored group; a Mann-Whitney U-Test (comparison of medians); $b$ Wilcoxon Signed Ranks Test (comparison of medians); Data presented as median (interguartile range); ${ }^{*} P<0.05$, statistically significant; $\quad{ }^{*}$ Comparison between groups; $P<0.05 ; \quad{ }^{* *}$ Comparison to basal value in Group $1, P<0.05 ; \quad$ *** Comparison to basal value in Group 2, $P<0.05$.

than Group 2. The number of patients needing tenoxicam consumptions between Group 1 and Group 2 at $4^{\text {th }}$ hour [10 $(28.6 \%)$ versus $35(94.6 \%) ; p<0.001], 12^{\text {th }}$ hour [23 $(65.7 \%)$ versus $35(94.6 \%) ; p=0.002$ ], and $24^{\text {th }}$ hour [9 $(25.7 \%)$ versus $32(86.5 \%) ; p<0.001$ ], were significantly different.

In comparison of intra- and postoperative complications in Group 1 and Group 2, there was no statistically significant relationship between increase in anxiety levels and hypotension [7 (20\%) versus $10(27 \%)$; $p=0.483$ ], bradycardia [2 $(5.7 \%)$ versus $3(8.1 \%)$; $p=0.69]$. When assessing the effect of anxiety on intraoperative vasopressor use, although vasopressor was administered in $1(2.7 \%)$ patient in Group 2, no patient in Group 1 required vasopressor $(p=0.327)$.

While the postoperative shivering rate in Group 2 was higher, this difference between the groups was not statistically significant [6 (17.1\%) versus 14 (37.8\%); $p=0.09]$. When the satisfaction rates of the patients were compared, the number of satisfied patients in Group 1 was found statistically significantly higher $(p<0.001)$. There was no significant difference in hospital length of stay (2.03 \pm 1.92 days versus $3.03 \pm 2.87$ days; $p>0.05$ ) between the groups.

\section{DISCUSSION}

Patients hospitalised for surgery face a major problem that defined as preoperative anxiety, this is also triggered emotional, mental and physical problems. ${ }^{10}$ These anxieties and fears may depend on the type of anesthesia, as well as previous experience of the patient, personality traits, concerns about surgical intervention, and pain in the postoperative period. ${ }^{11}$ That is adversely influence all of the anaesthesia stages, from hospital admission to discharge. ${ }^{12}$ Reseachers indicated a relationship between preoperative anxiety and raised sympathetic-parasympathetic system ripple and extra anesthetic need, higher frequency of nausea and vomiting, enhanced postoperative pain. It is reported that the duration of hospitalisation and healing term is prolonged due to these complications. ${ }^{13}$ 
The level of anxiety before interventional procedures affects the feeling of comfort and pain level of patients during the process in the negative direction. Preoperative evaluation and operation preparation is performed during the preoperative visit. There is no definite timeframe for when the preoperative visit should be. The anxiety scores calculated before the surgery and the anxiety scores calculated just before the operation and in the operating room are similar. ${ }^{8}$ For this reason, the anxiety tests in this study were applied during the preoperative anesthesia visit the night before the operation, so that it could be answered in a wider range of time and comfortably.

Domar et al. in 523 case studies, found anxiety score to be 45.0 on average according to STAI scale. ${ }^{14}$ The mean anxiety score of $42.01 \pm 15.04$ in this study is compatible with the literature. Conflicting results between preoperative anxiety levels and ages are available in the literature. Sun et al. reported high anxiety level in patients under 40 years of age. 15 However, there are also studies that advocate the increasing age and level of anxiety and link this to a more effective fatalism in the elderly and to easier adaptation of cultural factors and life stresses. ${ }^{16}$ Celik et al. found that if age progresses, patients efforts to reach information are decreasing. ${ }^{17}$ According to another study, the reason for this is that elderly patients associate their bad experiences with fate. On the other hand, young patients can access any information more easily than geriatric population by using communication sources. ${ }^{18}$ Another study, which showed that age did not affect anxiety level, had found to be similar to this study of the majority of middle-aged patients. ${ }^{19}$

When the relationship between gender and preoperative anxiety level is examined; preoperative anxiety level was higher in females compared to males. ${ }^{12}$ Badner et al. argued that this depended on the separation of women from their families; 19 Shevde et al. attributed this to the ability to express themselves more easily about their mental state. ${ }^{16}$ In Weinstock's research, hormonal changes effects on mood and anxiety disorders in women; in this way explain source of the dissimilarity by gender. ${ }^{20}$ However, there are also studies showing that gender does not affect the level of anxiety. ${ }^{21}$ In this study, in which 48 female and 24 male patients were examined, gender was not affected on anxiety according to the literature.

Studies on education level and anxiety level have different results. There is a positive correlation between the level of education and the level of anxiety in the literature.16,17 According to Cauomo et al., it was found that when education level increased, anxiety levels increased.21 As a result of the increase in education level, patients can get more detailed information about surgery and anesthesia and express their concerns more easily. But there are also studies suggesting that there is no relationship between education level and anxiety scores. ${ }^{14,15}$ Similar to the literature, there was no significant relationship between educational level and anxiety level in this patient population with moderate and low educational level.

The requirement for knowledge is much greater in patients without past anesthesia and surgical experience. 22 Nonanesthetised patients information scores more than patients who have already anaesthesia experience. ${ }^{17}$ There was also a significant decrease in anxiety levels in patients who underwent surgery and anesthesia experience previously. 19,21,23 However, in other studies it was shown that previous anesthesia experience did not affect the level of anxiety, ${ }^{18,24}$ which was to be consistent with this study. The authors think that the results of the patients' health when they are hospitalised may affect the differences in the studies.

According to the theory that explains biological anxiety, the autonomic nervous system in the anxious person is slowly adapting to the repetitive stimulus, while the moderate stimulus is overreacting. ${ }^{25}$ The source of these significant changes in intraoperative heart rate, contractile strength and peripheral vascular resistance, result of increased cortisol secretion is hypothalamuspituitary adrenal axis activation. 19 The observation of greater hemodynamic changes in these patients with high anxiety scores in the light of the above information supports researches. ${ }^{4}$

Preoperative high levels of anxiety can lead to prolonged hospital stay and postoperative complications. ${ }^{13,19}$ The increased level of anxiety in this study was associated with an increase in hospital stay. Some postoperative complications, such as delayed wound healing with high anxiety level in the preoperative period, may cause prolonged hospitalisation. There is a need for wider research that examines the effects of preoperative anxiety levels on postoperative complications.

\section{CONCLUSION}

The preoperative anxiety might cause hemodynamic problems in the intraoperative period, increased analgesic need, and lower postoperative satisfaction of the patients in the postoperative period. All the reasons having been mentioned, it would be better to dispel the preoperative anxietys in terms of patient, anesthesiolog, surgeon, and the institute by counselling.

\section{ETHICAL APPROVAL:}

This study was conducted in the operating room of the Trakya University Hospital after approval from University's Ethics Review Committee (Reference number: TÜTFBAEK 2015/198).

\section{CONFLICT OF INTEREST:}

Authors declared no conflict of interest. 


\section{AUTHORS' CONTRIBUTION:}

AB: Created the hypothesis or idea of research/article; organised, conducted and took responsibility for the conduct of the study/research, follow-up of patients, regulation and reporting of data taking responsibility for conducting experiments; took responsibility for evaluating and concluding the findings in a logical manner; took responsibility for the necessary resource screening; took responsibility for writing allor part of the work, provided financial resources and tools.

GS: Created the hypothesis or idea of research/article; organized, conducted and took responsibility for the conduct of the study/research, follow-up of patients, regulation and reporting of data taking responsibility for conducting experiments, took responsibility for evaluating and concluding the findings in a logical manner, took responsibility for the necessary resource screening, took responsibility for writing the work, prior to the submission of the study, re-evaluating the scientific study independently of language and literary arrangements, provided financial resources and tools.

EC: Created the hypothesis or idea of research/article, took responsibility for evaluating and concluding the findings in a logical manner, prior to the submission of the study, re-evaluated the scientific study independently of language and literary arrangements.

\section{REFERENCES}

1. Zeleníková R, Homzová P, Homza M, Bužgová R. Validity and reliability of the Czech version of the Amsterdam preoperative anxiety and information scale (APAIS). J Perianesth Nurs 2017; 32:429-37.

2 Woldegerima YB. Fitwi GL, Yimer HT, Hailekiros AG. Prevalence and factors associated with preoperative anxiety among elective surgical patients at University of Gondar Hospital, Gondar, Northwest Ethiopia, 2017. A cross-sectional study. Int J Surg Open 2018; 10:21-9.

3. Spielberger CD, Gorsuch RL, Lushene R. Manual for the statetrait anxiety inventory. Palo Alto, CA: Consulting psychologists press; 1983.

4. Kim WS, Byeon GJ, Song BJ, Lee HJ. Availability of preoperative anxiety scale as a predictive factor for hemodynamic changes during induction of anesthesia. Korean $J$ Anesthesiol 2010; 58:328-33.

5. Balasubramaniyan N, Rayapati DK, Puttiah RH, Tavane P, Singh SE, Rangan V, et al. Evaluation of anxiety induced cardiovascular response in known hypertensive patients undergoing exodontia - A prospective study. J Clin diag Res 2016; 10: ZC123-7.

6. Khanzada FJ, Soomro N, Khan SZ. Asociation of physical exercise on anxiety and depression amongst adults. J Coll Physicians Surg Pak 2015; 25:546-8.

7. Ghaffar R, Iqbal Q, Khalid A, Saleem F, Hassali MA, Baloch NS, et al. Frequency and predictors of anxiety and depression among pregnant women attending tertiary healthcare institutes of Quetta City, Pakistan. BMC Womens Health 2017; 17:2-8.

8. Kiyohara LY, Kayano LK, Oliveira LM, Yamamoto MU, Inagaki MM. Surgery information reduces anxiety in the preoperative period. Rev Hosp Clin Fac Med Sao Paulo 2004; 59:51-6.

9. Gordon DB, Polomano RC, Pellino TA, Turk DC, McCracken LM, Sherwood G, et al. Revised American pain society patient outcome questionnaire (APS-POQ-R) for quality improvement of pain management in hospitalized adults: Preliminary psychometric evaluation. J Pain 2010; 11:1172-86.

10. Buonanno P, Laiola A, Palumbo C, Spinelli G, Terminiello V, Servillo $G$. Italian validation of the Amsterdam preoperative anxiety and information scale. Minerva Anestesiol 2017; 83:705-11.

11. Mc Cleane GJ, Cooper R. The nature of preoperative anxiety. Anesthesia 1990; 45:153-5.

12. Laufenberg-Feldmann R, Kappis B. Assessing preoperative anxiety using a questionnaire and clinical ratings: A prospective observational study. Eur J Anaesthesiol 2013; 30:758-63.

13. Pokharel K, Bhattarai B, Tripathi M, Khatiwada S, Subedi A. Nepalese patients' anxiety and concerns before surgery. J Clin Anesth 2011; 23:372-8.

14. Domar AD, Everett LL, Keller MG. Preoperative anxiety: Is it a predictable entity? Anesth Analg 1989; 69:763-7.

15. Sun GC, Hsu MC, Chia YY, Chen PY, Shaw FZ. Effects of age and gender on intravenous midazolam premedication: A randomized double-blind study. Br J Anaesth 2008; 101:632-39.

16. Shevde K, Panagopoulos G. A survey of 800 patients knowledge, attitudes, and concerns regarding anesthesia. Anesth Analg 1991; 73:190-8.

17. Celik F, Edipoglu IS. Evaluation of preoperative anxiety and fear of anesthesia using APAIS score. Eur J Med Res 2018; 23:41.

18. Aykent R, Kocamanoglu I, Üstün E, Tür A, Sahinoglu H. The reasons and evaluation of preoperative anxiety: A comparison of APAIS and STAI scores. Turkiye Klinikleri J Anest Reanim 2007; $5: 7$.

18. Badner NH, Nielson WR, Munk S, Kwiatkowska C, Gelb AW. Preoperative anxiety detection and contributing factors. Can $\mathrm{J}$ Anaesth 1990; 37:444-7.

20. Weinstock LS. Gender differences in the presentation and management of social anxiety disorder. J Clin Psychiatry 1999; 60:9-13.

21. Kirdemir P, Ozorak O. Can postoperative pain and analgesic need be predicted in preoperative period. Turkiye Klinikleri $J$ Med Sci 2011; 31:951-9.

22. Caumo W, Schmidt AP, Schneider CN, Bergmann J, Iwamoto CW, Bandeira $D$, et al. Risk factors for preoperative anxiety in adults. Acta Anaesthesiol Scand 2001; 45:298-307.

23. Mohd Fahmi Z, Lai LL, Loh PS. Validation of the Malay version of the Amsterdam preoperative anxiety and information scale (APAIS). Med J Malaysia 2015; 70:243-8.

24. Buonanno P, Laiola A, Palumbo C, Spinelli G, Terminiello V, Servillo $G$. Italian validation of the Amsterdam preoperative anxiety and information scale. Minerva Anestesiol 2017; 83:705-11.

25. Noyes R, Hoehn- Saric R. Anksiyete bozukluklari (çeviri: V. Sar). Istanbul: Medical and Paramedical Yayincilik. 1998; 1-29. 